\title{
EFEITOS DA APLICAÇÃO DE REGULADORES VEGETAIS NA CULTURA DA ALFACE (Lactuca sativa) CRESPA var. Verônica e AMERICANA var. Lucy Brow.
}

\author{
REPKE, Rodrigo Alberto ${ }^{1}$ \\ VELOZO, Murilo Rodrigues ${ }^{2}$ \\ DOMINGUES, Marcio Christian.Serpa ${ }^{3}$ \\ RODRIGUES, João Domingos ${ }^{4}$
}

Recebido em: 2009-05-02

Aprovado em: 2009-09-22

ISSUE DOI: $10.3738 / 1982.2278 .203$

RESUMO: A alface é uma hortaliça folhosa de maior valor comercial cultivada no Brasil, com cerca de 75 variedades comerciais. É considerada planta de propriedades tranqüilizantes, com elevado teor de vitamina $\mathrm{A}, \mathrm{B}$ e C, além de cálcio, fósforo, potássio e outros minerais. O Presente trabalho teve como objetivo avaliar os efeitos do bioregulador stimulate sobre os aspectos fisiológicos e produtivos da cultura da alface crespa variedade "Verônica" e alface americana variedade "Lucy Brow". O ensaio foi desenvolvido em propriedade comercial de hortaliças folhosas, situada no município de Fernão, estado de São Paulo, com 6 tratamentos em delineamento de blocos ao acaso, com quatro repetições e dezesseis plantas por parcela, totalizando seis tratamentos, T1- testemunha, T2- 75ml.100L $\mathrm{L}^{-1}$, T3$100 \mathrm{ml} .100 \mathrm{~L}^{-1}$, T4- $125 \mathrm{ml} .100 \mathrm{~L}^{-1}$, T5- $150 \mathrm{ml} 100 \mathrm{~L}^{-1}$, T6- $175 \mathrm{ml} .100 \mathrm{~L}^{-1}$ de stimulate. Os parâmetros avaliados foram: Teor de clorofila, diâmetro dos plantas de alface, peso médio das plantas, numero médio de folhas por planta e incidência de queima de bordos nas folhas. Para a variedade crespa "Verônica" observou-se aumento significativo no desenvolvimento vegetativo com maior peso médio das plantas especificamente em dosagem de $150 \mathrm{ml}^{.100 \mathrm{~L}^{-1}}$ do biorregulador. Com relação a elevação do teor de clorofila a variedade americana "Lucy Brow" apresentou maior teores em uma concentração de $100 \mathrm{ml} . \mathrm{L}^{-1}$ do Stimulate.

Palavra-chave: Lactuca sativa. Reguladores vegetais. Desenvolvimento.

\section{EFFECTS OF APPLICATION OF PLANT GROWTH REGULATORS ON CULTURE OF THE CURLY LETTUCE (Lactuca sativa var. Veronica) AND AMERICAN LETTUCE (Lactuca sativa var. Lucy Brow)}

SUMMARY: The lettuce is a vegetable leafy of larger commercial value cultivated in Brazil, for about 75 commercial varieties. Plant of tranquilizing properties is considered, with high vitamin tenor A, B and C, besides calcium, match, potassium and others mine. The Present work had as objective evaluates the agronomic efficiency of the plant growth regultors on the physiologic and productive aspects of the culture of the lettuce curly variety "Veronica" and lettuce American variety "Lucy Brow". The rehearsal was developed in commercial property of vegetables leafy, located in the municipal district of Fernão, state of São Paulo, in a completely randomized, with four

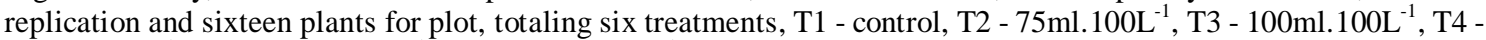
$125 \mathrm{ml} .100 \mathrm{~L}^{-1}, \mathrm{~T} 5-150 \mathrm{ml} .100 \mathrm{~L}^{-1}$, T6 $-175 \mathrm{ml} .100 \mathrm{~L}^{-1}$ of plant growth regulator stimulate. The evaluation parameters were accomplished during the crop about the following determinations: Chlorophyll rates, diameter of the heads of lettuce, medium weight of the feet, number of leaves and incidence of it burns of boards. In a "Veronica", significant increase was observed in a vegetative development and medium weight of the plants specifically in dosage of

\footnotetext{
${ }^{1}$ Acadêmico do curso de Engenharia Agronômica. Universidade de Marília. Marilia/SP. repkrodri@hotmail.com

${ }^{2}$ Engenheiro Agrônomo autônomo. Lençóis Paulista/SP. murilo_velozo@ hotmail.com

${ }^{3}$ Prof. Dr. Universidade de Marília. Marília/SP. sdomingues@ hotmail.com

${ }^{4}$ Prof. Titular. Instituto Biociências. UNESP. Botucatu/SP. mingorodrigues@ hotmail.com
} 
$150 \mathrm{ml} .100 \mathrm{~L}^{-1}$, regarding elevation of the chlorophyll rates the American variety "Lucy Brow" presented larger rates in a concentration of $100 \mathrm{ml} . \mathrm{L}^{-1}$ of Stimulate.

Kerwords: Lactuca sativa. Plant growth regulator. Development.

\section{INTRODUÇÃOO}

A alface é uma hortaliça folhosa de maior valor comercial cultivada no Brasil, por cerca de 75 variedades comerciais. É considerada planta de propriedades tranqüilizantes, com elevado teor de vitamina A, B e C, além de cálcio, fósforo, potássio e outros minerais (CASTELLANE et al, 1990).

A alface é uma cultura hortícola de grande valor alimentar, constituindo-se em componente imprescindível das saladas, onde representa a quarta hortícola em importância, ficando logo a seguir a batata, tomate e cebola, em ordem de importância, tanto pela área ocupada, quanto pelo valor das produções (MELLO et al, 2003).

O consumo per capita da alface é de $1,2 \mathrm{Kg} / \mathrm{ano}$, considerado baixo pela organização mundial de saúde (MELLO et al, 2003).

No estado de São Paulo, a alface ocupa 7859 ha, produzindo 137.000 ton/ano, gerando 6367 empregos. Os principais municípios fornecedores são Piedade, com 18\% da produção do estado, Mogi das Cruzes, com 14\% e Suzano, com 11\%, sendo o restante distribuído por outros municípios. A cultura apresenta elevado grau tecnológico, sendo comum as práticas de produção em ambiente protegido, hidroponia e cultivo orgânico, que permite obter verduras de qualidade o ano todo (HORTIBRASIL, 2006).

As auxinas são hormônios endógenos com grande diversidade de efeitos fisiológicos sobre os vegetais e são utilizadas comercialmente em função de cada interesse econômico, que se busca no fenótipo de plantas cultivadas (DAVIES, 2004)

Dentre os efeitos fisiológicos, relevantes na aplicação exógena de bioestimulantes, como o Stimulate, que apresenta auxina na sua composição: alongamento celular, que ocorre nas células jovens de folhas e meristemas, refletindo no alongamento de caule; divisão celular, que também está diretamente associada ao alongamento celular, bem como diferenciação celular do floema e do xilema (DAVIES, 2004)

Outro efeito fisiológico de relevada importância econômica das auxinas é a redução da senescência de folhas, retardo na abscisão de órgãos, desenvolvimento de partes florais, responsáveis pela produtividade, e ainda distribuição de fotoassimilados no vegetal em função do local de maior concentração de auxina, que se torna dreno mais forte, relacionado a translocação de solutos via floema (DAVIES, 2004) 
As giberelinas também atuam efetivamente no desenvolvimento de vegetais quando aplicada exógenamente, podendo estar associada ou não a outros grupos hormonais, como auxinas e citocininas, e que, semelhante às auxinas, também atuam no desenvolvimento do caule das plantas, em função do alongamento e divisão celular (semelhante às auxinas), e ainda pegamento de frutos e seu desenvolvimento, principalmente com a sua aplicação exógena (DAVIES, 2004)

As citocininas, como outros grupos hormonais atuam efetivamente na divisão celular e diferenciação celular, antagonicamente às auxinas, promovem brotações laterais, favorecendo maior desenvolvimento dos vegetais. Este efeito atua diretamente na expansão de folhas em função do alongamento celular, muito bem associado a expansão do sistema radicular, promovido efetivamente pelas citocininas encontradas nos meristemas radiculares, em função da concentração endógena, ou mesmo a pulverização via foliar (exógena). Somando-se a este efeito, há também o retardo da senescência, associado ao maior acúmulo do pigmento clorofila, com a maior conversão de etioplastos (precursores) em cloroplastos (DAVIES, 2004).

A senescência foliar é um tipo de programação que as células apresentam, que desencadeia a sua morte, caracterizado pela degradação da clorofila, lipídios, proteínas e RNA, processo este que está associado à evolução; ocorre também a mobilização de nutrientes dos tecidos vegetativos para órgãos reprodutivos (MCCABE, 2001).

A senescência pode ser induzida por estresses ambientais, como baixa intensidade luminosa, deficiência nutricional, ataques de patógenos, estresse hídrico e a própria separação do órgão da planta, associada a fatores endógenos, como a idade do órgão e desenvolvimento reprodutivo (MC CABE, 2001). Os reguladores vegetais estão diretamente ligados neste processo, como as auxinas, giberelinas e citocininas, enfocando principalmente a citocinina, pela elevada atuação nos cloroplastos e clorofila.

Plantas em processo de senescência apresenta redução da concentração endógena de citocinina, e a aplicação exógena retarda tal processo e ainda atua na manutenção e promoção do desenvolvimento vegetativo (MC CABE, 2001).

O retardo da senescência de hortaliças folhosas, foi reportado por Rossit; DeQuoy (1982), que aplicou GA, 2,4-D (auxina), ácido ascórbico e EDTA em plantas de alface, e que tais reguladores elevaram a vida útil das plantas em 300\%, estando associada a degradação da clorofila (AHARONI, 1989).

Em cultura de alface, a aplicação exógena de reguladores vegetais tem grande efeito no seu desenvolvimento vegetativo e reprodutivo. Abid et al. (1999) aplicaram via foliar $\mathrm{GA}_{3}$, nas concentrações entre 50 e $100 \mathrm{mg} . \mathrm{L}^{-1}$, durante o início do seu desenvolvimento, promoveu 
elevação significativa no tamanho de folhas em até 23\%, comparando-se com as plantas de alface não tratadas, conseqüentemente elevando-se também o peso dos pés de alface, especificamente

quando a temperatura ambiente não for considerada ideal para o desenvolvimento das alfaces, a $18{ }^{0} \mathrm{C}$.

Kochancov et al. (1996) aplicando $\mathrm{GA}_{3}$ individualmente em plantas de alface crespa, nas concentrações de $6,25 \mathrm{mg} . \mathrm{L}^{-1}, 12,5 \mathrm{mg} . \mathrm{L}^{-1}$ e $25 \mathrm{mg} . \mathrm{L}^{-1}$, favoreceram o florescimento de plantas, quando aplicado na menor concentração, em plantas de 3 a 20 folhas. Já a aplicação das duas maiores concentrações promoveu o crescimento excessivo, quando aplicado nas plantas de alface de 7 folhas, mostrando efeitos deletérios, como desordens morfogenéticas, como a curvatura do caule, e a formação de uma segunda cabeça.

Além do desenvolvimento da parte aérea, os reguladores vegetais também promovem o desenvolvimento do sistema radicular de plantas de alface. Segundo Jiang; Zhou (2000), plantas de alface tratadas com $10 \mathrm{mg} . \mathrm{L}^{-1}$ de NAA (ácido naftaleno acético - auxina), IBA (ácido indol butírico - auxina) e IAA (ácido indol acético - auxina), durante a fase inicial do desenvolvimento (após o transplantio), elevou o desenvolvimento do sistema radicular em 67\%, em relação às plantas não tratadas.

Diante disso, o presente ensaio de pesquisa teve por objetivo avaliar a eficiência agronômica do Stimulate sobre os aspectos fisiológicos e produtivos da cultura da alface crespa variedade "Verônica" e alface americana variedade "Lucy Brow".

\section{MATERIAIS E MÉTODOS}

O presente ensaio foi desenvolvido em propriedade comercial de hortaliças folhosas, Verduras Sato, situada no município de Fernão, estado de São Paulo, localizado nas coordenadas geográficas $22^{0} 21^{\prime} 31^{\prime \prime}$ de latitude sul e $49^{0} 31^{\prime} 15^{\prime \prime}$ de longitude oeste.

O ensaio foi desenvolvido à campo, em canteiros de alface (Lactuca sativa) recém transplantados, de 1,20 × $50 \mathrm{~m}$, em espaçamentos de $0,30 \mathrm{~m} \times 0,30 \mathrm{~m}$, com altura média de $15 \mathrm{~cm}$, as variedades crespa "Verônica" e americana "Lucy Brow" .

As mudas de alface, foram oriundas de produção em bandejas de polietileno, de 128 células, sobre ambiente protegido, ideal para a produção de hortaliças folhosas, na mesma propriedade, com idade média de 20 dias, a partir da semeadura.

A área de cada parcela constou de $1,5 \mathrm{~m} \times 1,2 \mathrm{~m}\left(1,8 \mathrm{~m}^{2}\right)$ com 16 plantas, numa área total por bloco de $12,6 \mathrm{~m}^{2}$ (7 tratamentos), totalizando $50,4 \mathrm{~m}^{2}$ a área total do ensaio.

As aplicações do bioestimulante Stimulate foram realizadas periódicamente, que se iniciaram 1 semana após o transplantio, conforme Figura 1, prolongando-se até a colheita das 
plantas, e totalizou 8 aplicações, pela manhã, após a primeira irrigação do dia, realizada nos canteiros, que era por aspersão, numa lâmina d'água de 6 mm/dia.

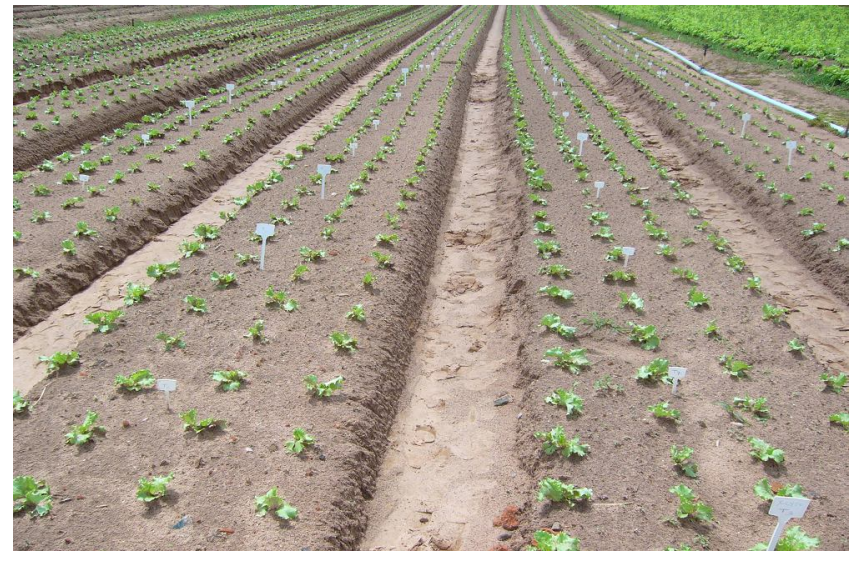

FIGURA 1. Vista geral do ensaio, na data da primeira aplicação do Bioestimulante Stimulante na cultura da alface crespa (Lactuca sativa var. "Verônica") e alface americana (Lactuca sativa var. "Lucy Brow"), durante a colheita, 30 dias após o início da aplicação foliar do Stimulate. Fernão/SP, abril/2006.

\section{Tratamentos}

Dosagem (ml/100 L)

Época

Aplicações

T1 - Controle

\begin{tabular}{ll}
\hline T2 - STIMULATE & 75 \\
\hline T3 - STIMULATE & 100 \\
\hline T4 - STIMULATE & 125 \\
\hline T5 - STIMULATE & 150 \\
\hline T6 - STIMULATE & 175
\end{tabular}

Semanalmente, do

transplante à colheita
Pulverizações

Foliares

QUADRO 1. Dosagens do Stimulate aplicado em solução aquosa, época de aplicação e metodologia de aplicação na cultura do alface (Lactuca sativa) variedade Crespa "Verônica" e americana "Lucy Brow". Fernão, 2006.

O bioestimulante comercial utilizado foi o Stimulate, do registrante Stoller do Brasil Ltda, que contém em sua formulação $90 \mathrm{mg} . \mathrm{L}^{-1}$ de cinetina (citocinina), $50 \mathrm{mg} . \mathrm{L}^{-1}$ de $\mathrm{GA}_{3}$ (giberelina) e $50 \mathrm{mg} . \mathrm{L}^{-1}$ de IBA (auxina), aplicado em solução aquosa com um adjuvante a base de óleo vegetal na concentração de $0,5 \%$ do produto comercial Natur'l Óleo, que contém 93\% de óleo vegetal, registrado pela Stoller do Brasil Ltda. O volume de calda utilizado foi de 555 Lha $^{-1}$ (400 ml de solução por tratamento).

O delineamento Experimental implantado foi em Blocos ao acaso, com 4 repetições de 16 plantas por parcela, totalizando 6 tratamentos.

Os parâmetros avaliados foram realizados durante a colheita da cultura da alface, realizando-se as seguintes determinações: 
- TEOR DE CLOROFILA: realizado nas folhas medianas das plantas de alface, com o clorofilômetro modelo SPAD-502 (Minolta, Japão), em 6 folhas por planta de cada parcela, escolhidas aleatoriamente entre os pés de alface, e dados expressos em unidades aleatórias do teor de clorofila.

- DIÂMETRO DOS PÉS: realizado com uma régua, determinando-se o maior diâmetro da planta, em 3 plantas por parcela, totalizando 12 dados coletados por tratamento.

- PESO MÉDIO DOS PÉS DE ALFACE: após a colheita dos pés de alface, eram submetidos a pesagem em balança digital, num total de 3 plantas por parcela.

- NÚMERO MÉDIO DE FOLHAS: as folhas foram separadas do caule, procedendo-se a sua contagem.

- INCIDÊNCIA DE QUEIMA DE BORDOS: analisada em cada planta colhida, observando-se as folhas das plantas que apresentavam qualquer sintoma fisiológico de queima de bordos, causado por deficiência momentânea de cálcio, em função de sua baixa translocação, associada ao rápido desenvolvimento da cultura.

\section{RESULTADOS E DISCUSSÃO}

A aplicação do bioestimulante Stimulate, que contém auxinas, giberelinas e citocinas no mesmo produto, promoveu elevação nos teores de clorofila, quando aplicados na cultura de alface (Lactuca sativa) var. americna Lucy Brow durante seu desenvolvimento vegetativo, como demonstra a Tabela 1, desde a concentração mais baixa até a mais elevada, culminando nos teores, para a dosagem de $100 \mathrm{ml} . \mathrm{L}^{-1}$ de Stimulate. O mesmo efeito na alteração do teor de clorofila não ocorreu para a alface crespa var. Verônica, que naturalmente já apresenta menores teores de clorofila nas folhas, e não sendo afetada pela aplicação do Stimulate (Tabela 1).

TABELA 1. Teor médio de clorofila em folhas de alface crespa (Lactuca sativa var. Verônica) e alface americana (Lactuca sativa var. Lucy Brow), durante a colheita, 30 dias após o início da aplicação foliar do Stimulate. Fernão/SP, abril/2006 
Teor de clorofila (unidades aleatórias)

Tratamentos Dosagem de

\begin{tabular}{cccc} 
& Stimulate (ml/100 L) & $\begin{array}{c}\text { Alface crespa } \\
\text { "Verônica" }\end{array}$ & $\begin{array}{c}\text { Alface americana } \\
\text { "Lucy Brow" }\end{array}$ \\
\hline T1. Controle & 0 & $11,97 \mathrm{a}$ & $22,40 \mathrm{~b}$ \\
\hline T2. Stimulate & 75 & $12,27 \mathrm{a}$ & $22,98 \mathrm{ab}$ \\
\hline T3. Stimulate & 100 & $11,39 \mathrm{a}$ & $25,14 \mathrm{a}$ \\
\hline T4. Stimulate & 125 & $12,30 \mathrm{a}$ & $23,16 \mathrm{ab}$ \\
\hline T5. Stimulate & 150 & $12,05 \mathrm{a}$ & $24,78 \mathrm{ab}$ \\
\hline T6. Stimulate & 175 & $12,00 \mathrm{a}$ & $24,07 \mathrm{ab}$ \\
\hline CV $(\%)$ & & 4,97 & 6,46
\end{tabular}

Médias seguidas de mesma letra na vertical, não diferem entre si pelo Teste Duncan ao nível de 5\% de probabilidade.

Trabalhos de pesquisa mostram os maiores efeitos da aplicação de reguladores vegetais na cultura da alface, que contém citocininas, com objetivo de elevar o período pós-colheita, com menor degradação da clorofila, mas que não ocorre ainda com a planta em desenvolvimento, como foi observado por Aharoni (1989), que aplicou auxinas, e obteve redução da senescência das plantas em até $300 \%$, quanto a questão de tempo pós colheita.

Porém, os efeitos da aplicação do Stimulate sobre o desenvolvimento da planta de alface (Lactuca sativa) foi bastante significativo quando aplicado em todas as concentrações utilizadas do bioestimulante, desde 75 até $175 \mathrm{ml} 100 \mathrm{~L}^{-1}$ em ordem crescente da dosagem, para as duas variedades de alface. O efeito sobre o desenvolvimento das plantas foi avaliado através da determinação do diâmetro das plantas, de acordo com a Tabela 2. Tal efeito no alongamento celular, que reflete no aumento do tamanho das plantas, concorda com Davies (2004), que cada vez mais afirma a importância da aplicação dos reguladores vegetais, especificamente auxinas, giberelinas e citocininas na promoção da qualidade de plantas, quando recebem tais grupos hormonais via pulverização foliar.

O desenvolvimento das plantas de alface também foram obtidos por Abid et al., (1999), Kochancov et al., (1996) e Jiang; Zhou (2000), com a aplicação de reguladores vegetais que contém os mesmos grupos hormonais presentes no Stimulate, e inclusive, quando aplicado em dosagens elevadas promoveu efeitos deletérios para a cultura, como desordens morfológicas ou mesmo o florescimento, especificamente para concentrações elevadas de $\mathrm{GA}_{3}$.

TABELA 2. Diâmetro médio dos pés de alface crespa (Lactuca sativa var. "Verônica") e alface americana (Lactuca sativa var. "Lucy Brow"), durante a colheita, 30 dias após o início da aplicação foliar do Stimulate. Fernão/SP, abril/2006.

Diâmetro médio $(\mathrm{cm})$

Tratamentos 


\begin{tabular}{cccc}
\hline & $\begin{array}{c}\text { Dosagem de } \\
\text { Stimulate }(\mathrm{ml} / 100 \mathrm{~L})\end{array}$ & $\begin{array}{c}\text { Alface crespa } \\
\text { "Verônica" }\end{array}$ & $\begin{array}{c}\text { Alface americana } \\
\text { "Lucy Brow" }\end{array}$ \\
\hline T1. Controle & 0 & $31,90 \mathrm{~b}$ & $35,66 \mathrm{~b}$ \\
\hline T2. Stimulate & 75 & $36,55 \mathrm{a}$ & $39,08 \mathrm{a}$ \\
\hline T3. Stimulate & 100 & $36,05 \mathrm{a}$ & $38,58 \mathrm{a}$ \\
\hline T4. Stimulate & 125 & $35,54 \mathrm{a}$ & $39,16 \mathrm{a}$ \\
\hline T5. Stimulate & 150 & $36,25 \mathrm{a}$ & $38,66 \mathrm{a}$ \\
\hline T6. Stimulate & 175 & $37,12 \mathrm{a}$ & $39,16 \mathrm{a}$ \\
\hline CV $(\%)$ & & 4,29 & 2,77
\end{tabular}

Médias seguidas de mesma letra na vertical, não diferem entre si pelo Teste Duncan ao nível de 5\% de probabilidade.

TABELA 3. Peso médio dos pés de alface crespa (Lactuca sativa var. "Verônica") e alface americana (Lactuca sativa var. "Lucy Brow"), durante a colheita, 30 dias após o início da aplicação foliar do Stimulate. Fernão/SP, abril/2006.

\section{Peso médio (gramas)}

Tratamentos Dosagem de

\begin{tabular}{cccc} 
& Stimulate $(\mathrm{ml} / 100 \mathrm{~L})$ & $\begin{array}{c}\text { Alface crespa } \\
\text { "Verônica" }\end{array}$ & $\begin{array}{c}\text { Alface americana } \\
\text { "Lucy Brow" }\end{array}$ \\
\hline T1. Controle & 0 & $310,69 \mathrm{~b}$ & $826,43 \mathrm{a}$ \\
\hline T2. Stimulate & 75 & $370,04 \mathrm{ab}$ & $742,85 \mathrm{a}$ \\
\hline T3. Stimulate & 100 & $353,01 \mathrm{ab}$ & $780,65 \mathrm{a}$ \\
\hline T4. Stimulate & 125 & $345,91 \mathrm{ab}$ & $793,96 \mathrm{a}$ \\
\hline T5. Stimulate & 150 & $376,86 \mathrm{a}$ & $840,20 \mathrm{a}$ \\
\hline T6. Stimulate & 175 & $362,67 \mathrm{ab}$ & $833,37 \mathrm{a}$ \\
\hline CV $(\%)$ & & 11,03 & 15,44
\end{tabular}

Médias seguidas de mesma letra na vertical, não diferem entre si pelo Teste Duncan ao nível de 5\% de probabilidade.

O efeito conhecido do Stimulate sobre o desenvolvimento vegetal também foi comprovado nesta aplicação sobre a cultura de alface. Como pode ser observado na Tabela 2, que demonstra o efeito no desenvolvimento, o peso médio das plantas também se elevou, especificamente para a variedade Crespa Verônica, conforme pode ser visualizado na Tabela 3, onde toda as aplicações utilizadas de Stimulate foram responsivas, especificamente para a dosagem de $150 \mathrm{ml} .100 \mathrm{~L}^{-1}$. Já para a variedade americana Lucy Brow, não houve efeito significativo na elevação de peso das plantas, provavelmente pela formação da cabeça mais fechada, com pouca exposição à aplicação do biorregulador, e maior compactação das folhas jovens sobre elas mesmas. 
TABELA 4. Número médio de folhas de alface crespa (Lactuca sativa var. Verônica), durante a colheita, 30 dias após o início da aplicação foliar do Stimulate. Fernão/SP, abril/2006.

N. de folhas

\begin{tabular}{ccc} 
Tratamentos & $\begin{array}{c}\text { Dosagem de Stimulate } \\
(\mathrm{ml} / 100 \mathrm{~L})\end{array}$ & $\begin{array}{c}\text { Alface crespa } \\
\text { "Verônica" }\end{array}$ \\
\hline T1. Controle & 0 & 24,75 a \\
\hline T2. Stimulate & 75 & 28,25 a \\
\hline T3. Stimulate & 100 & 30,50 a \\
\hline T4. Stimulate & 125 & 28,00 a \\
\hline T5. Stimulate & 150 & 29,00 a \\
\hline T6. Stimulate & 175 & 29,50 a \\
\hline CV $(\%)$ & & 19,18
\end{tabular}

Médias seguidas de mesma letra na vertical, não diferem entre si pelo Teste Duncan ao nível de 5\% de probabilidade.

Quanto ao número médio de folhas de plantas de alface crespa Var. Verônica, não houve emissão de maior número de folhas. Tal parâmetro está também associado ao desenvolvimento das plantas, porém o desenvolvimento vegetal observado nas Tabelas 2 e 3 ocorreu em função do alongamento celular elevado promovido pelos grupos hormonais auxinas, giberelinas e citocininas, presentes no Bioestimulante Stimulate, e não por aumentar o número médio de folhas por planta. O número médio de folhas para a alface americana Var. Lucy Brow não foi avaliado, pois a planta tem formação bastante significativa de cabeça, com folhas bastante fechadas sobre elas mesmas, com elevada densidade do órgão.

TABELA 5. Incidência de queima de bordos das folhas de alface crespa (Lactuca sativa var. Verônica) e alface americana (Lactuca sativa var. Lucy Brow), durante a colheita, 30 dias após o início da aplicação foliar do Stimulate. Fernão/SP, abril/2006.

N. de folhas com queima de bordos*

Tratamentos Dosagem de

\begin{tabular}{ccc} 
Stimulate $(\mathrm{ml} / 100 \mathrm{~L})$ & $\begin{array}{c}\text { Alface crespa } \\
\text { "Verônica" }\end{array}$ & $\begin{array}{c}\text { Alface americana } \\
\text { "Lucy Brow" }\end{array}$ \\
\hline 0 & $2,0 \mathrm{a}$ & 0,0 \\
\hline 75 & $0,75 \mathrm{a}$ & 0,0 \\
\hline 100 & $1,75 \mathrm{a}$ & 0,0 \\
\hline 125 & $1,75 \mathrm{a}$ & 0,0 \\
\hline 150 & $2,25 \mathrm{a}$ & 0,0
\end{tabular}




\begin{tabular}{|c|c|c|c|}
\hline T6. Stimulate & 175 & $1,50 \mathrm{a}$ & 0,0 \\
\hline $\mathrm{CV}(\%)$ & & 66,31 & 0,0 \\
\hline
\end{tabular}

Médias seguidas de mesma letra na vertical, não diferem entre si pelo Teste Duncan ao nível de 5\% de probabilidade.

* Dados transformados.

Em relação à incidência da queima de bordos de folhas de alface, primariamente causadas pela deficiência relativa de cálcio, nas folhas mais novas em desenvolvimento, desordem fisiológica bastante significativa para a cultura, principalmente pelo rápido desenvolvimento das folhas da alface, que ocorre em função das condições climáticas que favorecem tal deficiência momentânea.

No presente ensaio, a incidência de queima de bordos foi relativamente de pouca ocorrência, mesmo nas plantas que não receberam a aplicação do Stimulate, em plantas de alface crespa var. "Verônica", que pode ser observado também na Figura 3, e nenhuma incidência em folhas de alface da variedade americana var. "Lucy Brow" (Tabela 5).

$\mathrm{O}$ efeito de reguladores vegetais sobre desordens fisiológicas, especificamente do cálcio, devido a sua baixa translocação, e que os reguladores vegetais tornam a relação fontedreno mais forte, ou seja, há maior translocação de nutrientes para os drenos, que neste caso são as folhas, que receberam a aplicação do Stimulate (DAVIES, 2004).

\section{CONCLUSÃO}

- A aplicação de Stimulate na cultura da alface promoveu efeitos positivos no desenvolvimento das plantas, elevando o teor de clorofila em alface americana, var. "Lucy Brow", diâmetro médio das plantas e peso das plantas de alface crespa var. "Verônica"

- Não houve interferência da aplicação do Stimulate, em promover o florescimento das plantas em função da baixa concentração de $\mathrm{GA}_{3}$ presente no produto, capaz somente de estimular o desenvolvimento vegetativo

- Quanto a queima de bordos, desordem fisiológica muito importante para a cultura, não houve incidência, mesmo com a elevação do desenvolvimento da planta, ou seja, sem efeitos deletérios da aplicação do Stimulate para a cultura.

\section{REFERÊNCIAS}

ABID, A.; MALIK, F. R.; QUADRI, R. B. Studies on pre-harvest foliar treatments of gibberellic acid and the effect of temperature on the growth and yield of Lactuca sativa L. cv. Empire and Vanguard. Bangladesh Journal of Scientific and Industrial Research, v.34, n.1, p.91-94, 1999.

CASTElllane, P. D.; NICOLOSI, W.M.; HASEGAWA, M. Produção de sementes e hortaliças. FCAV/Funep. Jaboticabal. 1990, p.1-13. 
DAVIES, P. J. (ed.). Plant hormones. Biosynthesis, signal transduction, action. Kluwer Academic Publishers. Dordrecht, 2004. 750p.

HORTIBRASIL. Programa Brasileiro para a modernização da horticultura. Disponível em: www.hortibrasil.org.br. Acesso em: 15 maio 2006, 22:45h.

JIANG, L.; ZHOU, X. The effect of auxins and cytokinins on the formation of lateral root primordial and the contents of endogenous hormones in lettuce seedlings. Journal of Nanjing Agricultural University, v.23, n.1, p.19-22, 2000.

KONCHANKOV, V.G. et al. Effect of gibberellic acid on growth, flowering, and seed production in crisphead lettuce (Lactuca sativa L.). Folia Horticulturae, v.8, n.1, p.11-18, 1996.

MELLO, J.C.; DIETRICH, R. et al. Efeito do cultivo orgânico e convencional sobre a vida de prateleira da alface Americana (Lactuca sativa L.) minimamente processada. Ciência e Agrotecnologia de Alimentos, v.23, n.3, p. 418-426, 2003.

ZHANG, N.G.; HASENSTEIN, K.H. Initiation and elongation of lateral roots in Lactuca sativa. International Journal of Plant Science, v.160, n.3, p.511-519, 1999. 